\title{
Adenovirus type 8 conjunctivitis outbreak in a neonatal intensive care unit
}

\author{
Emanuel Birenbaum, Nehama Linder, Noemi Varsano, Roberto Azar, Jacob Kuint, \\ Abraham Spierer, Brian Reichman
}

who had undergone ophthalmological examination four to seven days previously. Second and third waves of this outbreak occurred after seven and 14 days and affected a total of nine staff and 12 family members of patients and staff (see figure).

\section{VIROLOGICAL METHODS}

For virus identification, specimens were inoculated in three different cell types, $\mathrm{Hu}-\mathrm{Ki}$ (human kidney carcinoma cells), A-549 (human lung carcinoma cells), and MRC-5 (human lung fibroblasts). Type identification was performed by specific immune serum neutralisation. ${ }^{4}$

Chaim Sheba Medical Center, Tel-Hashomer and the Sackler School of Medicine, Tel-Aviv University, Tel-Aviv, Israel, Department of Neonatology Emanuel Birenbaum Nehama Linder Jacob Kuint

Brian Reichman

Central Virology

Laboratory

Noemi Varsano

Roberto Azar

Department of

Ophthalmology

Correspondence to:

Dr Birenbaum.

Accepted 21 December 1992
Abraham Spierer

Adenovirus infection is the principal pathogen in epidemics of conjunctivitis or keratoconjunctivitis. $^{1}$ The most frequently detected strain is type 8 adenovirus, although types 11 , 19 , and 37 have also been isolated. ${ }^{2}$ A recent review of adenovirus infection in neonates documents systemic invasion of the virus causing severe disease. ${ }^{3}$ However, cases of adenovirus type 8 conjunctivitis were not reported.

This report describes an epidemic of adenovirus type 8 conjunctivitis in premature infants in hospital and documents the systemic effects of the infection in this population.

\section{Patients and methods}

Within a four day period, severe conjunctivitis developed in four of seven premature infants

$$
\begin{array}{ccc}
\text { 1st wave } & \text { 2nd wave } & \text { 3rd wave } \\
(n=7) & (n=13) & (n=8)
\end{array}
$$

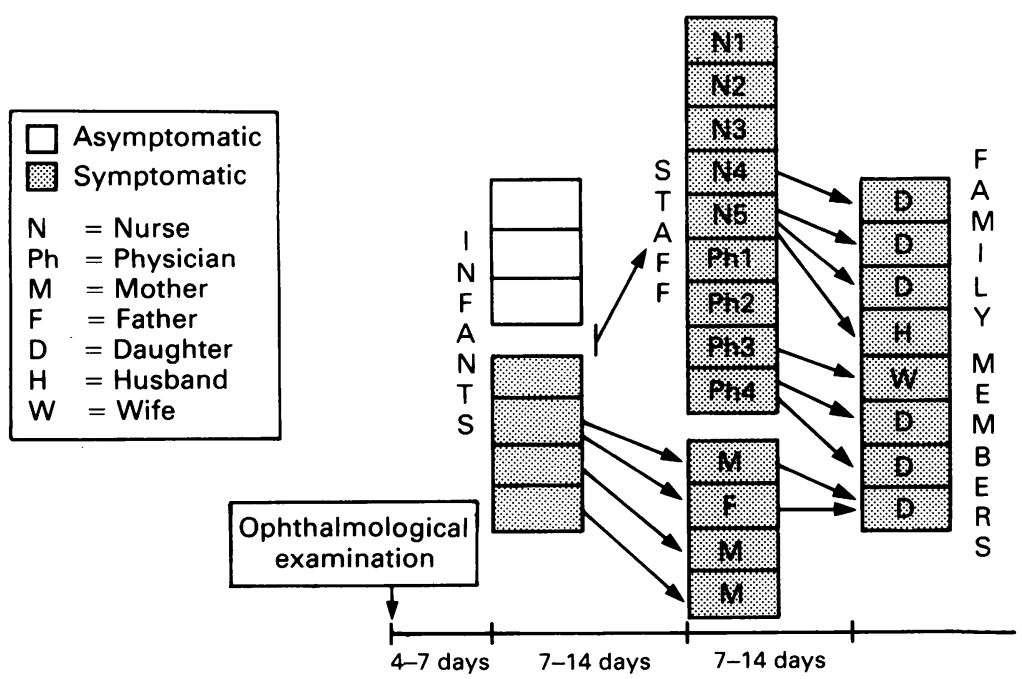

Subjects affected by adenovirus type 8 in three waves of the outbreak. The left hand column represents the seven premature infants who underwent ophthalmological examination before the outbreak.

\section{Results}

Viral cultures revealed adenovirus type 8 in four symptomatic and three asymptomatic infants who had undergone ophthalmological examination before the onset of the epidemic. The clinical characteristics of the seven infected infants are shown in the table. All four symptomatic infants had previously required mechanical ventilation; three had bronchopulmonary dysplasia and were treated with supplemental oxygen, dexamethasone, and diuretics at the time of the outbreak. The fourth infant was treated with amphotericin B. In the asymptomatic group two infants had previously been mechanically ventilated and neither suffered from chronic lung disease. All four symptomatic infants initially developed acute unilateral conjunctivitis followed by bilateral congestion and oedema of the conjunctiva and eye lids. Ectropion of the eye lids, periorbital celullitis, and conjunctival haemorrhage, occurred in one patient each.

Systemic manifestations of the infection were noted in the three infants with chronic lung disease. The patients were all febrile and lethargic and showed deterioration of their preexisting respiratory disease with tachypnoea and a marked increase in oxygen requirement. The white cell count decreased from a mean of $13.3 \times 10^{9} / 1$ (range $11.5-15 \cdot 1$ ) to $7.6 \times 10^{9} / 1$ (range 5.4-9.3), and the platelet count decreased simultaneously from a mean of $433 \times 10^{9} / 1$ (range $411-450$ ) to $120 \times 10^{9} / 1$ (range 97-202). Fever and haematological abnormalities remitted within a week while local manifestations such as conjunctivitis and respiratory distress persisted for three to four weeks. Ophthalmological examination after three months did not show evidence of corneal sequelae. 
Clinical characteristics of infants infected with adenovirus type 8

\begin{tabular}{|c|c|c|c|c|c|c|}
\hline $\begin{array}{l}\text { Gestational } \\
\text { age } \\
\text { (weeks) }\end{array}$ & $\begin{array}{l}\text { Birth } \\
\text { weight } \\
\text { (g) }\end{array}$ & Diagnosis & $\begin{array}{l}\text { Age at } \\
\text { outbreak } \\
\text { (weeks) }\end{array}$ & $\begin{array}{l}\text { Weight } \\
(g)\end{array}$ & $\begin{array}{l}\text { No of eye } \\
\text { examinations } \\
\text { before } \\
\text { outbreak }\end{array}$ & $\begin{array}{l}\text { Treatment } \\
\text { before } \\
\text { outbreak }\end{array}$ \\
\hline $\begin{array}{l}\text { Symptomatic } \\
25\end{array}$ & 680 & Hyaline membrane disease, bronchopulmonary & 38 & 4600 & 24 & $\begin{array}{l}\text { Oxygen, dexamethasone } \\
\text { cryotherapy }\end{array}$ \\
\hline 26 & 905 & $\begin{array}{l}\text { Hyaline membrane disease, bronchopulmonary } \\
\text { dysplasia, ROP III }\end{array}$ & 14 & 2850 & 10 & $\begin{array}{l}\text { Oxygen, dexamethasone } \\
\text { cryotherapy }\end{array}$ \\
\hline 29 & 1410 & $\begin{array}{l}\text { Ureaplasma pneumonia, bronchopulmonary } \\
\text { dysplasia, ROP III }\end{array}$ & 6 & 1520 & 2 & Oxygen, dexamethasone \\
\hline 28 & 1195 & $\begin{array}{l}\text { Hyaline membrane disease, IVH II, Candida } \\
\text { albicans sepsis }\end{array}$ & 7 & 1430 & 3 & Amphotericin B \\
\hline $\begin{array}{l}\text { Asymptomatic } \\
31 \\
30 \\
28\end{array}$ & $\begin{array}{l}c \\
1000 \\
1135 \\
1090\end{array}$ & $\begin{array}{l}\text { Escherichia coli sepsis, recurrent apnoea, IVH II } \\
\text { PROM } \\
\text { Hyaline membrane disease, IVH II, } \\
\text { ROP II }\end{array}$ & $\begin{array}{l}5 \\
5 \\
8\end{array}$ & $\begin{array}{l}1300 \\
1410 \\
1430\end{array}$ & $\begin{array}{l}2 \\
1 \\
2\end{array}$ & $\begin{array}{l}- \\
- \\
-\end{array}$ \\
\hline
\end{tabular}

$\mathrm{IVH}=$ intraventricular haemorrhage, $\mathrm{PROM}=$ premature rupture of membranes, $\mathrm{ROP}=$ retinopathy of prematurity.

The second and third waves of the epidemic affected a total of 16 adults and six children. All developed severe bilateral conjunctivitis and most complained of myalgia, weakness, photophobia, severe pain, blurring of vision, and regional lymphadenopathy. Ocular manifestations persisted for three to four weeks.

Conjunctival cultures were positive for adenovirus type 8 in all seven premature infants. In addition, five of six throat cultures, two in symptomatic and three in asymptomatic infants, were positive as were all four rectal cultures taken from one symptomatic and three asymptomatic infants.

\section{Discussion}

Hospital outbreaks of adenovirus type 8 keratoconjunctivitis have suggested that direct inoculation of the virus by ophthalmological instruments is a common predisposing factor. ${ }^{1}$ A linear relationship between the number of eye examinations and the incidence of infection suggests that repetitive microtrauma to epithelium may facilitate pathogenic invasion of the virus. ${ }^{1}$ The seven infected infants had all undergone ophthalmological examination before developing conjunctivitis suggesting that this procedure was associated with the onset of the outbreak either by introducing the virus into the unit or by transmitting the virus from one previously infected infant to others. Systemic illness occurred, however, in only four of the seven infected infants. The severity of the underlying clinical condition in symptomatic infants, combined with prolonged treatment with steroids in three and amphotericin $\mathbf{B}$ in one, might have impaired their immunological status facilitating systemic invasion of the virus, ${ }^{56}$ and subsequent deterioration of the respiratory illness in patients with chronic lung disease.

Premature infants in neonatal intensive care units are subjected routinely to repeated ophthalmological examination for the identification of retinopathy of prematurity. These examinations may introduce or spread conjunctival infections and strict adherence to appropriate aseptic procedures may prevent this potentially hazardous complication.

1 D'Angelo LJ, Hierholzer JC, Holman RC, Smith JD. Epidemic keratoconjunctivitis caused by adenovirus type 8 Epidemiologic and laboratory aspects. Am $\mathcal{f}$ Epidemiol 1981; 113: 44-9.

2 Vastine DW, West CE, Yamashiroya H, et al. Simultaneous nosocomial and community outbreak of epidemic keratoconjunctivitis with type 8 and 19 adenovirus. Trans $P a$ Acad Ophthamol Otolaryingol 1976; 81: 826-40.

3 Abzug MJ, Levin MJ. Neonatal adenovirus infection: four patients and review of the literature. Pediatrics $1991 ; 87$ $890-6$.

4 Hierholzer JC. Adenovirus. In: Schmidt NJ, Emmons RW, eds. Diagnostic procedures for viral, rickettsial and chlamydial infections. Washington: APHA, 1989: 219-64.

5 Gunn T, Reece ER, Metrakos K, Colle E. Depressed T cells following neonatal steroid treatment. Pediatrics 1981; 67: following

6 Koren G, Lau A, Klein J, et al. Pharmacokinetics and adverse effects of amphotericin B in infants and children. $\mathcal{F}$ Pediatr 1988; 113: 559-63. 